\title{
Treatment resistance in psychiatry: state of the art and new directions
}

\author{
Oliver D. Howes ${ }^{1,2,3^{凶}}$, Michael E. Thase ${ }^{4}$ and Toby Pillinger (D) $^{1,2}$ \\ (c) The Author(s) 2021
}

\begin{abstract}
Treatment resistance affects $20-60 \%$ of patients with psychiatric disorders; and is associated with increased healthcare burden and costs up to ten-fold higher relative to patients in general. Whilst there has been a recent increase in the proportion of psychiatric research focussing on treatment resistance $\left(R^{2}=0.71, p<0.0001\right)$, in absolute terms this is less than $1 \%$ of the total output and grossly out of proportion to its prevalence and impact. Here, we provide an overview of treatment resistance, considering its conceptualisation, assessment, epidemiology, impact, and common neurobiological models. We also review new treatments in development and future directions. We identify 23 consensus guidelines on its definition, covering schizophrenia, major depressive disorder, bipolar affective disorder, and obsessive compulsive disorder (OCD). This shows three core components to its definition, but also identifies heterogeneity and lack of criteria for a number of disorders, including panic disorder, post-traumatic stress disorder, and substance dependence. We provide a reporting check-list to aid comparisons across studies. We consider the concept of pseudo-resistance, linked to poor adherence or other factors, and provide an algorithm for the clinical assessment of treatment resistance. We identify nine drugs and a number of non-pharmacological approaches being developed for treatment resistance across schizophrenia, major depressive disorder, bipolar affective disorder, and OCD. Key outstanding issues for treatment resistance include heterogeneity and absence of consensus criteria, poor understanding of neurobiology, under-investment, and lack of treatments. We make recommendations to address these issues, including harmonisation of definitions, and research into the mechanisms and novel interventions to enable targeted and personalised therapeutic approaches.
\end{abstract}

Molecular Psychiatry (2022) 27:58-72; https://doi.org/10.1038/s41380-021-01200-3

\section{INTRODUCTION}

The discovery of medications with clinically meaningful antidepressant and antipsychotic effects in the mid-twentieth century was a landmark in the treatment of mental disorders. However, soon afterwards it was recognised that in some patients, their condition showed limited or no response to these drugs [1-3]. Where an illness does not respond despite an adequate course of treatment, it is generally termed treatment resistant. Treatment resistance is now recognised across a range of psychiatric disorders, including schizophrenia, major depressive disorder (MDD), bipolar affective disorder [4], and obsessive compulsive disorder (OCD) [5]. Despite this, treatment resistance was not a focus of psychiatric drug development for decades and, to date, only one treatment, clozapine, is a licensed monotherapy for treatment resistance in psychiatry, and then specifically for schizophrenia. However, there are signs of change, with companies developing drugs for treatment resistance for a number of psychiatric disorders [6-8], and there is now broad recognition that a 'one size fits all' approach has reached the limits of effectiveness [9]. To evaluate research interest in treatment resistance in psychiatry, we conducted an analysis of scientific publications on treatment resistance in psychiatry between 2000-2019 inclusive (see eAppendix 1 for methods and full results). This shows a significant year-on-year increase in the number of papers published focussing on treatment resistance in psychiatry, after accounting for the increase in total number of publications over time $\left(\beta=0.84, R^{2}=0.71, p<0.0001\right.$, Fig. 1$)$. It is thus timely to review the concepts of treatment resistance used in psychiatry, its prevalence and burden across disorders, and to consider current and future therapeutic directions.

\section{The origins of the concept of treatment resistance}

The use of the term treatment resistance in psychiatry pre-dates the discovery of antipsychotics, antidepressants and mood stabilisers. More than a century ago, Freud used the term 'resistance' to describe unconscious mental reactions and behaviour exhibited during psychoanalysis that inhibited the response to therapy; identifying and addressing resistance is, in this context, considered therapeutic [10]. The term was also used in the 1930s when insulin coma therapy was used for schizophrenia, to describe the scenario where patients maintained consciousness despite delivery of large insulin doses [11]. Early reports of treatment resistance to antipsychotics and antidepressants did not include the Freudian concept of an unconscious mental reaction, but focused instead on inadequate symptomatic response to treatment [1-3]. This concept was crystallised in the

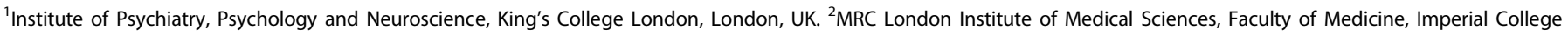

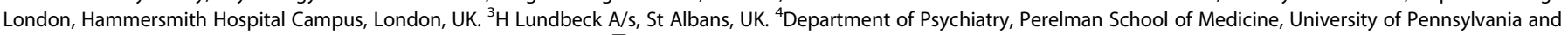
Corporal Michael J. Crescenz VA Medical Center, Philadelphia, USA. ${ }^{\bowtie}$ email: oliver.howes@kcl.ac.uk

Received: 18 February 2021 Revised: 26 May 2021 Accepted: 10 June 2021

Published online: 13 July 2021 


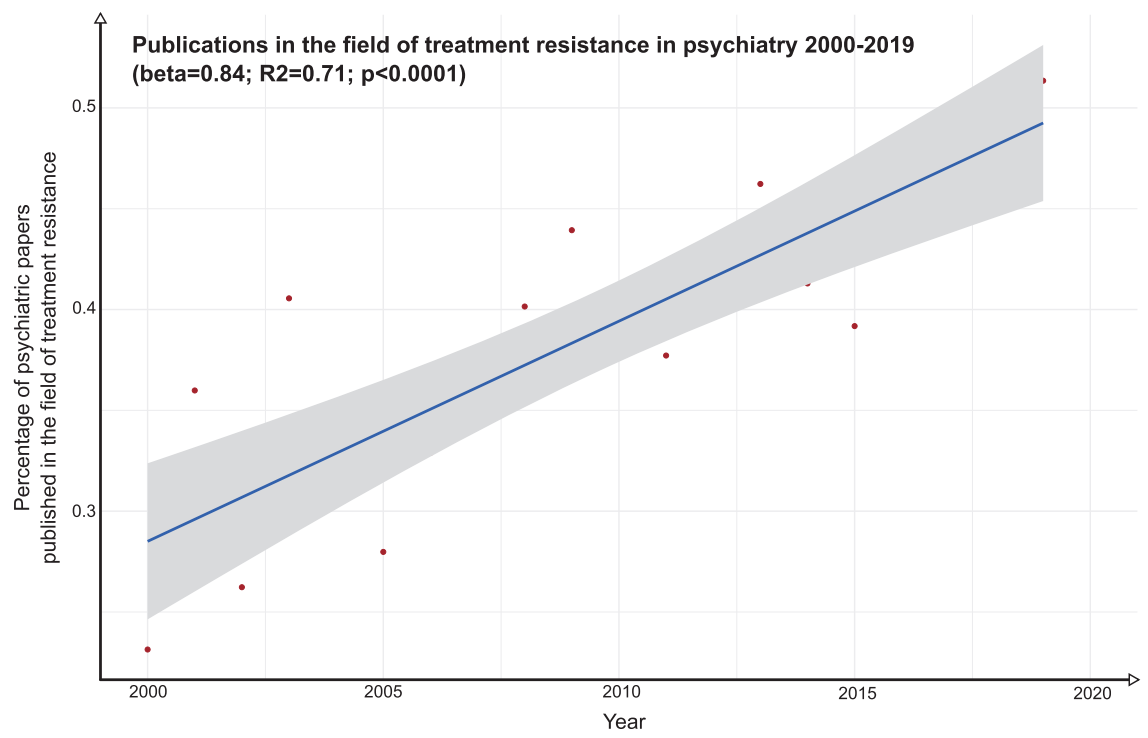

Fig. 1 Scatterplot showing the relationship between the number of papers published in the field of treatment resistance in psychiatry and time (2000-2019). The number of papers published on treatment resistance in psychiatry are presented as a percentage of the total number of publications in the field of psychiatry overall. The solid blue line corresponds to the regression estimate with the corresponding $95 \%$ confidence interval, indicated by grey shading, showing a significant increase in the percentage of psychiatric research focusing on treatment resistance over the last two decades.

late 1980s [12] with the demonstration of clozapine's efficacy over chlorpromazine in patients with schizophrenia whose illness had not responded to at least three previous antipsychotic trials. Since then, a number of criteria have been developed to define treatment resistance in different disorders.

\section{Current definitions of treatment resistance across disorders}

We conducted a systematic review of national and international consensus definitions of treatment resistance for common psychiatric diagnoses (see eAppendix 2 for full search strategy). This identified 23 guidelines: 9 for schizophrenia; 10 for depression; 1 for the depressed phase of bipolar affective disorder; and 3 for OCD. The criteria used in these guidelines are summarised in Table 1. These highlight three core components required to establish treatment resistance seen across disorders and guidelines; these are that the correct diagnosis has been made, that adequate treatment has been given, and that there has been inadequate response (see Fig. 2).

However, whilst these core components are seen in the definitions of treatment resistance across disorders, there is considerable variation in the specific criteria used between different disorders. Surprisingly, marked variation in criteria is also seen within the same psychiatric diagnoses, particularly regarding how adequate pharmacotherapy is defined and how response to treatment is assessed. For example, the number of treatment trials that an individual should receive prior to a diagnosis of treatment resistance is, for some criteria for OCD and depression, either not defined, or inconsistent, ranging between 2-3 different drugs for depression. Furthermore, certain criteria for schizophrenia, depression, and OCD recommend using different drug classes (e.g., ensuring a trial of first and second-generation antipsychotics in some criteria for schizophrenia), while others do not make this specification. Moreover, the target drug dose is often not defined, despite some conditions having well-described dose-equivalents at which clinical response is expected [13]. Thus, subtherapeutic trials of treatments may be erroneously considered adequate trials, leading to an over-inclusive classification of treatment resistance. For $O C D$, definitions of treatment trials also are inconsistent on whether or not psychological therapy should be included as a treatment alongside pharmacological therapy.
For some criteria, recommended treatment durations are either not defined, or range between 2-12 weeks. Treatments such as those delivered in long-acting injectable formulation may take months to reach steady state, thus there is the risk that shorter trials of certain medications may be inadequate $[14,15]$. There is also a lack of clarity regarding use of some neuro-stimulatory treatments. For example, although most MDD guidelines discuss use of transcranial magnetic stimulation as a therapeutic option, advice regarding its role in the context of treatment resistance, whether it should be used as monojunctive or adjunctive therapy, and what position it should take in a treatment algorithm for resistant symptoms is often not stated.

Inherent to the concept of treatment resistance is the idea that there is inadequate treatment response. Of the 23 guidelines identified, we observed that criteria for defining inadequate treatment response varied widely and were not provided in two definitions. Three defined inadequate treatment response in absolute terms using statements such as 'no effect', four recommended assessments of quantitative change in symptom severity using symptom rating scales and thresholds to define response, and fourteen used amorphous terms such as 'inadequate' or 'minimal' response. Failure to objectively quantify symptom severity increases risk of inter-rater variability, where one clinician may differ from another based on their subjective opinions of what constitutes treatment response. Using 'no effect' as a criterion is likely to be too restrictive in most clinical scenarios given natural variation in the course of disorder and placebo response [16], even without considering what level of therapeutic response might be adequate. In contrast, many criteria focus on definitions of failure to meet a minimum response threshold, which allows for natural variation and placebo response, but implies there may be a response, albeit inadequate. Failure to achieve a specific therapeutic response, but achieving a partial response to treatment, is not equivalent to no change in symptoms at all, particularly where the response threshold is high, and results in different conceptualisations of treatment resistance and potentially leading to very different patients being included in studies. Although defining response in a binary fashion is necessary to guide subsequent management (e.g., a change in medication), grouping patients together with putatively 


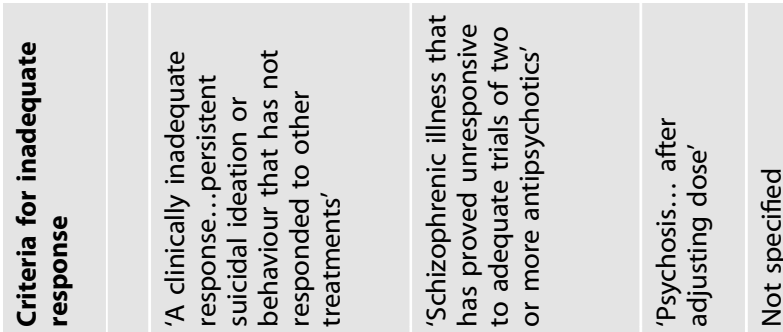

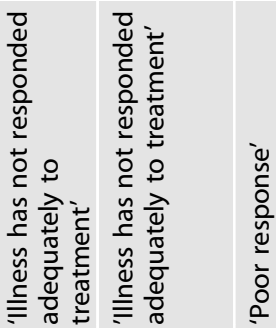

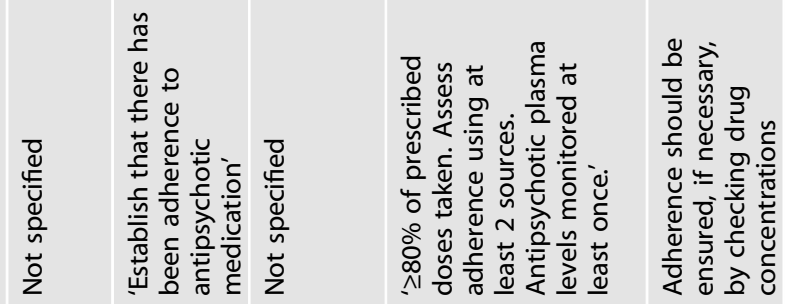

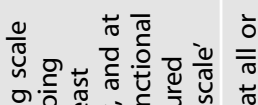

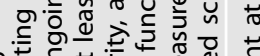

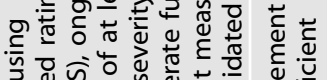
उ. जू气 है

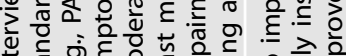
离

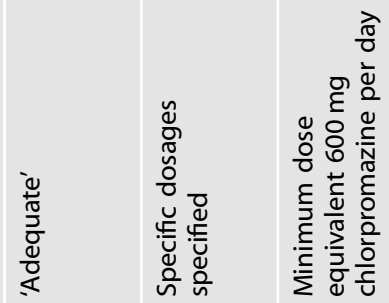

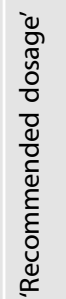

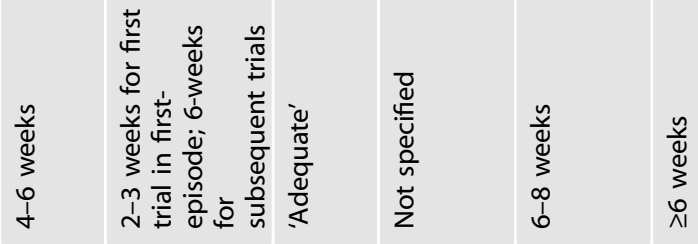

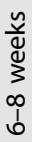

ปั

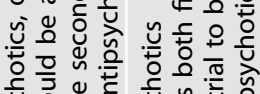

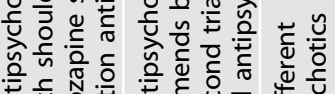

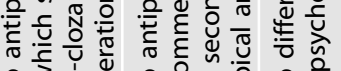

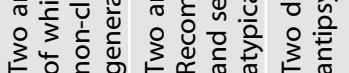

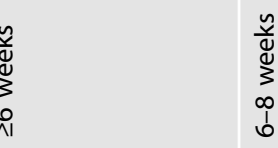

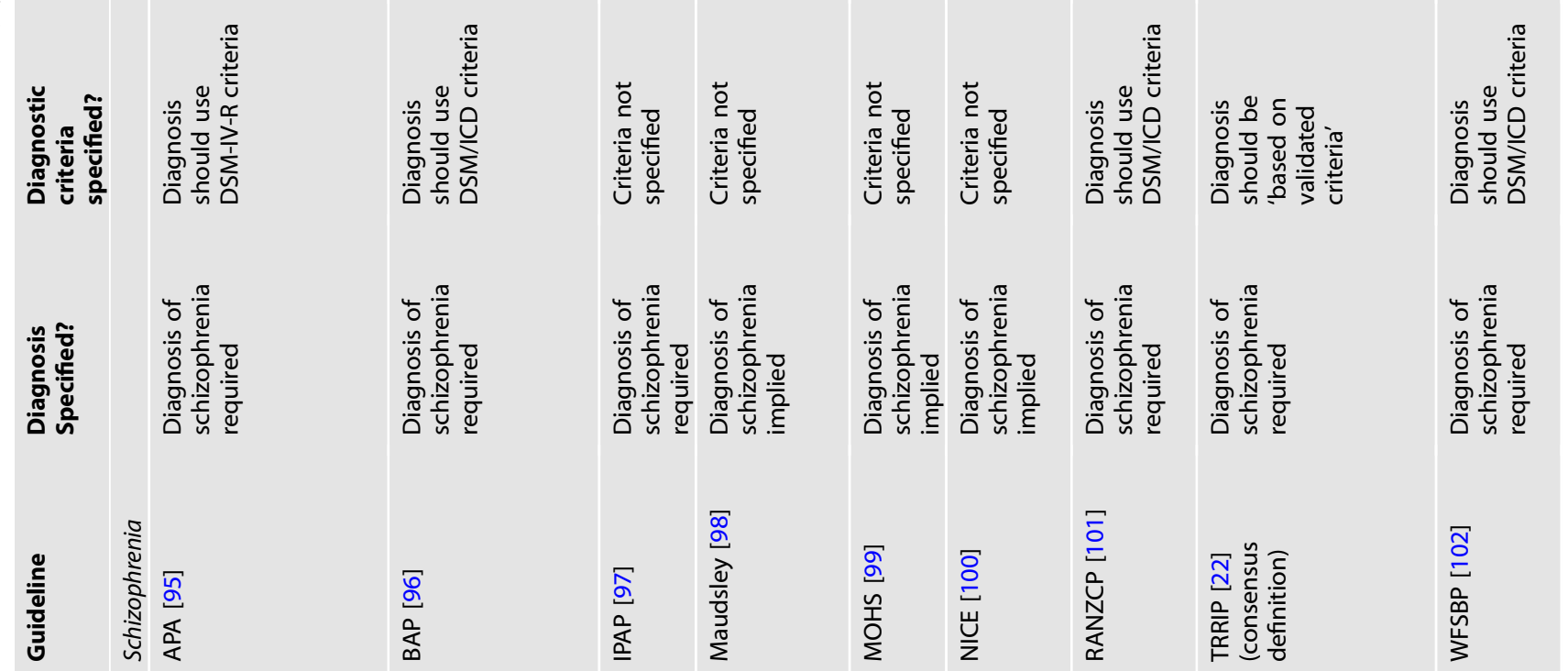



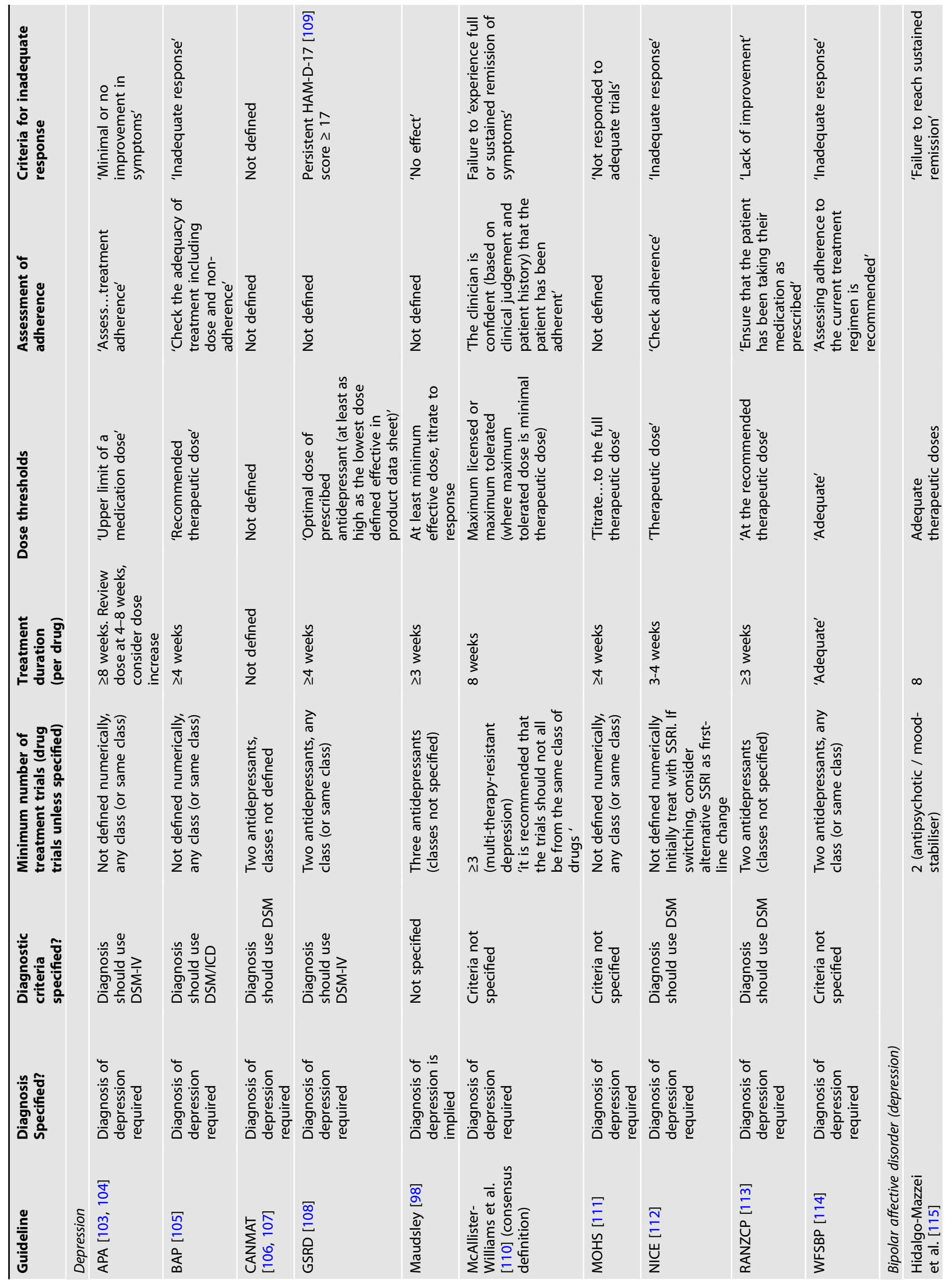


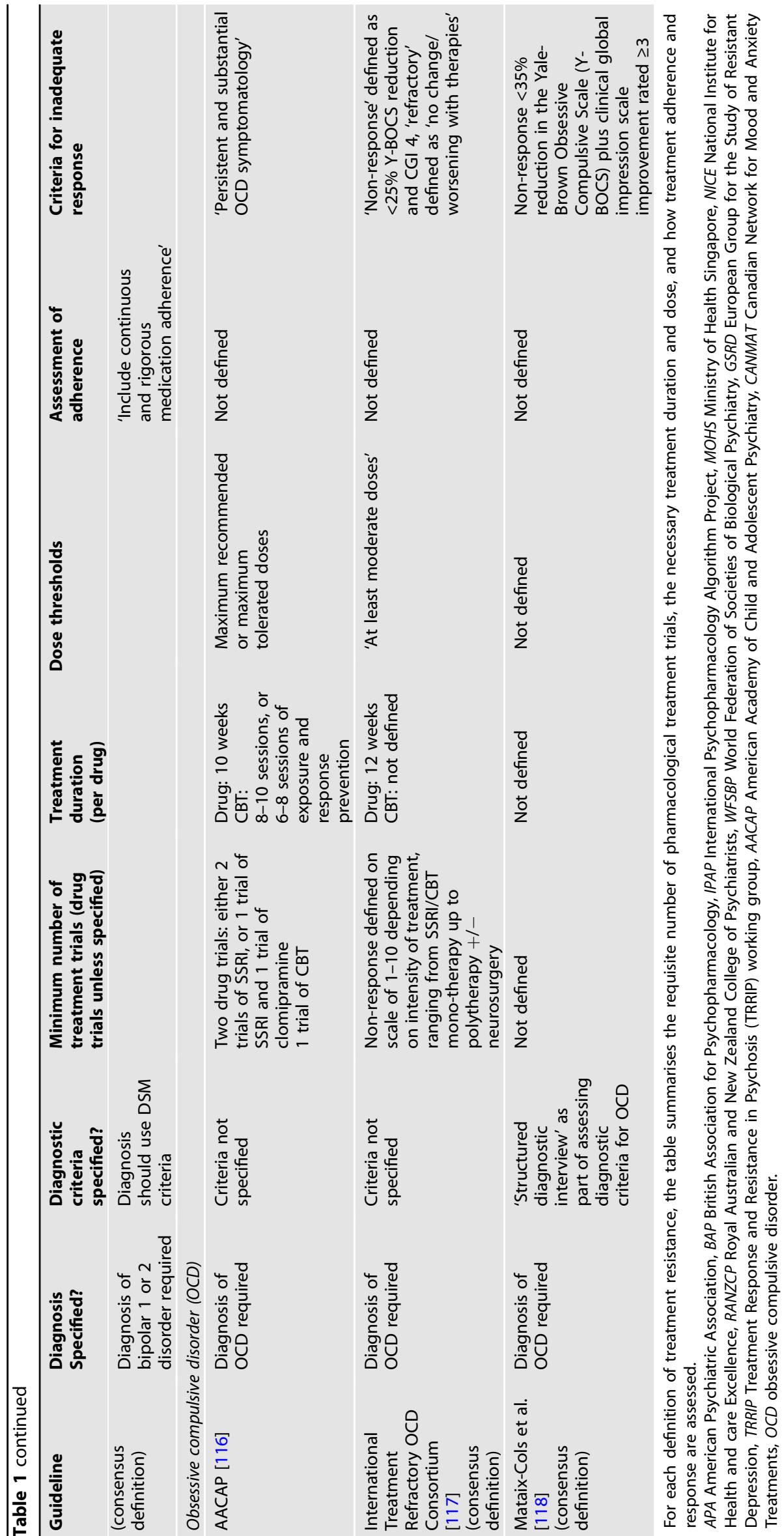




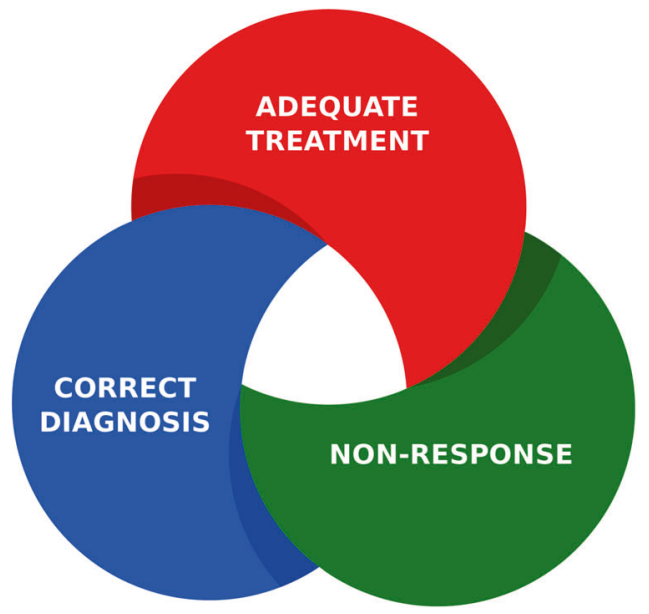

Fig. 2 Treatment resistance consists of three core components. Establishing treatment resistance requires concurrent confirmation of the following: 1) that the correct psychiatric diagnosis has been made; 2 ) that a patient has received adequate treatment; 3 ) that symptoms have not adequately responded despite treatment.

different presentations (i.e., absolute non-responders with partialresponders) may result in ineffective and inappropriate treatment being offered to certain patients. Partial response to a given pharmacological treatment could indicate that the drug is having some benefit, but the dose or duration of treatment may not be sufficient. In contrast, absolute non-response to treatment suggests the drug's mechanism of action is not relevant for this patient, and thus a treatment with a medication with an alternate mode of action may be more appropriate. The potential consequence of grouping partial-responders and absolute nonresponders together is that absolute non-responders may then be offered a treatment that is ineffective, and partial-responders may be unnecessarily offered riskier or experimental treatments. Inconsistency and lack of clarity in definitions of treatment resistance also has implications for interpretation of findings across clinical trials, as characteristics of patients in one study population may contrast markedly with the characteristics in another. Inconsistencies in definitions of treatment resistance between studies may be responsible for surprising results from meta-analyses examining efficacy of pharmacological treatments in treatment resistant psychiatric disorders $[17,18]$.

We were unable to identify operationalised definitions of treatment resistance for mania, panic disorder, post-traumatic stress disorder (PTSD) and substance dependence. This is surprising given the evidence that nonresponse to standard therapies is a common clinical challenge in the treatment of these disorders [19-21], and represents a key outstanding issue for the field. It is not clear why this is the case but may reflect the fact that drug treatments for some of these disorders are less well established than for conditions like schizophrenia and major depression. Another consideration for definitions is whether functional impact is needed in addition to on-going symptoms. Only one criterion required a quantitative assessment of functioning to define treatment response [22].

Finally, a core component of the concept of treatment resistance is that the patient has taken the prescribed medication. Despite this, Table 1 shows that assessment of medication adherence is rarely included as a criterion for treatment resistance, and only one guideline recommended checking plasma drug levels to assess adherence. Thus, there is a risk that non-adherent patients may be considered as treatment resistant, which has implications for clinical trials of drugs for treatment resistance. Over a third of patients with schizophrenia identified as 'treatment resistant' show evidence of poor adherence [23], and poor adherence is reported in $10-60 \%$ of patients with depression [24]; this could mean that a large proportion of patients entering a trial are non-adherent rather than treatment resistant, potentially obscuring an effect or biasing results. Non-adherence is one contributor to pseudo-resistance, which is considered in the next section. Table 1 also shows that, where adherence is mentioned, most of the guidelines use statements such as 'ensure adherence' or 'exclude poor adherence' without making clear what constitutes adherence or poor adherence.

Overall, our review of the criteria shows considerable variability and lack of specificity in definitions of treatment resistance across psychiatric disorders, which has both clinical and research implications. The lack of clear definitions and, thus, risk of marked differences in patient characteristics between studies could be addressed by the use of standardised rating scales with established psychometric properties coupled with operationalising criteria to provide clear cut-offs. Heterogeneity could be reduced by harmonising criteria across guidelines within a disorder. Difficulties in knowing if studies recruited similar patients could be addressed by using a reporting checklist for treatment resistance that make clear, how each of the three components of treatment resistance was established in patients, an example of which is provided in Box 1.

\section{Primary versus secondary treatment resistance}

Longitudinal studies indicate that trajectories to treatment resistance vary [25]. In some patients the illness shows an inadequate response to treatment from first presentation, whilst in others it initially shows a good response to treatment but over time this declines [25]. These prototypic trajectories have been respectively termed primary and secondary treatment resistance [26], although this terminology has been criticised as implying different mechanisms that are not known [22]. Alternatively, the descriptive terms 'early onset' and 'late onset' of treatment resistance may be used [22]. Notwithstanding discussions on terminology, this distinction is potentially important for research and clinical practice as it is unclear if treatments will be equally effective in these groups [22]. Putative neurobiological mechanisms for primary versus secondary treatment resistance are described below. Furthermore, a proportion of therapeutic benefit

\section{Box 1}

A treatment resistance reporting checklist for clinical trials and other studies to use in demonstrating on what basis patients with treatment resistant psychiatric disorders are recruited

\section{Correct diagnosis}

a. Was a standardised diagnostic tool used, and if so, what was it?

b. Was diagnostic stability confirmed, and if so, how was this assessed?

2. Adequate treatment

a. Was a prospective evaluation required?

b. What dose and duration of treatment was deemed to be an adequate trial?

c. How many adequate treatment trials were required?

d. Was adherence assessed, and if so how (e.g., use of drug plasma levels)?

3. Non-response

a. Was a prospective evaluation required?

b. How was response assessed? Specify the scales or tools used and time period.

c. If quantitatively assessed, what thresholds were used to distinguish adequate from inadequate response?

d. Was whether this is primary or secondary treatment resistance determined? If so, how? 
Table 2. Potential contributors to pseudo-resistance in schizophrenia and depression.

\begin{tabular}{ll}
\hline & Schizophrenia \\
$\begin{array}{l}\text { Drug plasma levels and } \\
\text { adherence }\end{array}$ & $\begin{array}{l}\text { Over one third of patients identified as 'treatment } \\
\text { resistant' show evidence of poor adherence [23] }\end{array}$
\end{tabular}

Genetic variants affecting trans-membrane transporters

Genetic variants affecting liver drug metabolism

Liver drug metabolism: influence of co-prescribed psychiatric medication

Liver drug metabolism: influence of co-prescribed physical health medication

Tobacco smoking

Sex

Alternative Diagnosis
P-glycoprotein transporter polymorphisms influence antipsychotic response in schizophrenia [120]

Both first-generation and second-generation antipsychotics plasma levels and/or efficacy reduced by some CYP1A2, 2D6 and 3A4 polymorphisms [122]

Co-prescription of psychiatric medications that act as CYP450 inducers (e.g., lamotrigine and carbamazepine) can reduce plasma levels of some antipsychotics [124]

Co-prescription of medications that act as CYP450 inducers (e.g., omeprazole, phenytoin, St John's wort, rifampicin) can reduce plasma levels of some antipsychotics [122]

Smoking reduces plasma levels of those antipsychotics metabolised via CYP1A2 (e.g., olanzapine, clozapine) [127]

Male gender predicts lower plasma levels of some antipsychotics [129]

Symptoms of other disorders, such as bipolar affective disorder, obsessive compulsive disorder or autism spectrum disorder, may be mistaken for schizophrenia [31, 32]

\section{Depression}

A cross-sectional study observed that $15 \%$ of patients with MDD presenting with poor clinical response to tricyclic antidepressant therapy had 'unusually low plasma concentrations relative to dose' [119]. Poor adherence is reported in $10-60 \%$ of patients with depression [24]

P-glycoprotein transporter polymorphisms predict treatment response in depression [121]

Ultra-rapid metabolizer capacity recognised with polymorphisms of certain CYP450 enzymes (e.g., CYP2D6 and CYP2C19) result in reduced plasma levels for several antidepressants, including TCAs, SSRIs and SNRIs, and influence clinical response [123]

Co-prescription of psychiatric medications that act as CYP450 inducers (e.g., lamotrigine, carbamazepine) can reduce plasma levels of some antidepressants, including TCAs, SSRIs and bupropion [125]

Co-prescription of medications that act as CYP450 inducers (e.g., St John's wort, phenytoin) may reduce plasma levels of some antidepressants [126]

Smoking reduces plasma concentrations of various antidepressants [128]

Male gender predicts lower plasma levels of some antidepressants [130]

A minority of apparently resistant unipolar depression may in fact be depression associated with bipolar disorder $[33,34]$

Further evidence is provided in eTable 1.

TCA tricyclic anti-depressant, SSRI selective serotonin reuptake inhibitor, SNRI serotonin and norepinephrine reuptake inhibitor.

is derived from non-specific effects, which may be larger earlier in the course of illness [27].

The distinction between primary and secondary treatment resistance is only referred to in one of the consensus statements or guidelines recorded in Table 1 [22]. In this context, it would be helpful for future studies to investigate if there are differences between patients with primary versus secondary treatment resistance in treatment outcomes or neurobiology. Where this is not possible or warranted, clear reporting of the relative proportion of patients with primary versus secondary treatment resistance would help enable comparisons with other studies.

\section{Pseudo-resistance: diagnostic and treatment-related factors}

Pseudo-resistance describes the circumstance where a patient's condition does not respond to treatment, but the criteria for treatment resistance have not been fulfilled; for example, because the diagnosis was incorrect or the exposure to treatment was not adequate. Diagnostic instability, especially early in the course of a mental illness, is well described [28]. For example, bipolar affective disorder may initially present with a major depressive episode and be treated as unipolar depression. If such a patient has a poor outcome because of a treatment emergent mixed state or worsening of selected symptoms (e.g., insomnia or agitation), the patient may be deemed to have treatment resistant depression, when in actuality the wrong treatment had been selected [29]. This scenario highlights the need to ensure careful history and assessment of patients and cautions against concluding treatment resistance after only a short presentation.
Another common cause of pseudo-resistance is an inadequate therapeutic trial of treatment. Psychiatric drugs need to cross the blood-brain barrier and bind to their target in the brain. Several factors can lead to insufficient drug reaching the target in the brain. These are summarised in Table 2 and Fig. 3 (see eTable 1 for additional evidence). They include non-concordance with treatment, poor absorption of oral medication at the level of the gut endothelia, fast metabolism of medication by the liver, and poor blood-brain-barrier penetrance of medication. Some treatments may also be associated with a bell-shaped dose-response curve, where increasing dose leads to increasing efficacy only up to a point, whereupon further dose increases lead to decreasing efficacy [30]; in this scenario, high doses of treatment may be responsible for pseudo-resistance.

\section{The clinical assessment of treatment resistance}

The clinical assessment of potential treatment resistance is summarised in Fig. 4. A key step is to rule out pseudo-resistance as far as possible (Table 2 and Fig. 3). As such, clinical assessment should rule out alternate psychiatric diagnoses, e.g., features of autism spectrum disorder or OCD which may be mistaken for schizophrenia [31, 32] or bipolar-type depression which may be mistaken for unipolar depression [33, 34]. Where possible, duration and severity of symptoms, associated distress, and level of functioning should be quantified using validated clinical rating scales, which facilitates objective and accurate longitudinal assessment of treatment response. A comprehensive medication history should be taken to ensure that previous psychiatric medication trials were adequate, documenting dose and duration, 


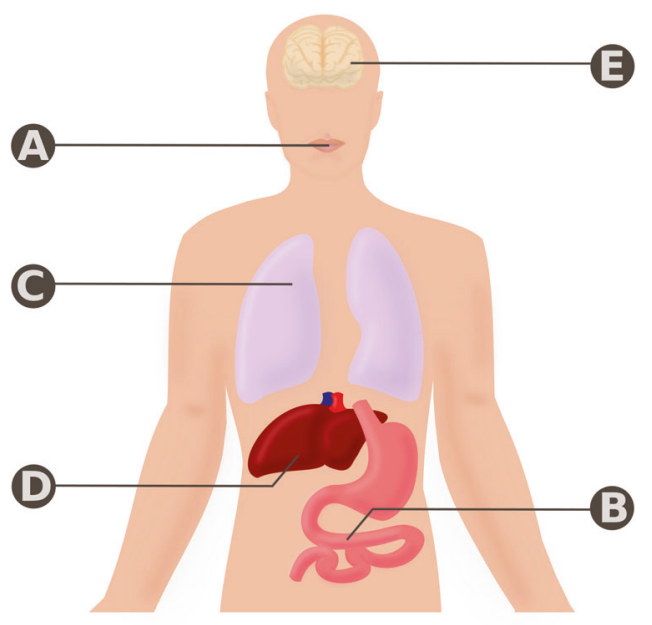

Fig. 3 Pseudo-resistance to treatment in psychiatry: treatment related factors. A Poor concordance with medication or forgetfulness may result in insufficient drug being taken to achieve a therapeutic response, B Polymorphisms in P-glycoproteins in the gut endothelia may result in poor absorption of drugs and insufficient drug exposure. C Smoking tobacco induces expression of CYP450 enzymes, particularly CYP1A2, in the liver (D) resulting in enhanced break down of psychiatric medication metabolised by these enzymes. Polymorphisms in CYP450 enzymes that enhance their activity or co-administration of other psychiatric/non-psychiatric medications that act as enzyme inducers will have a similar effect. E Poor brain accumulation of drug owing to poor blood brain barrier permeability and/or polymorphisms in P-glycoprotein may result in insufficient central nervous system drug levels to achieve a therapeutic response.

and associated response. Finally, current treatment should be defined, and plasma levels measured where possible. This process should allow the assessment of key factors requisite for determining treatment resistance summarised in Fig. 4.

\section{Epidemiology and impact of treatment resistance}

Prevalence estimates of TRS, TRD and treatment resistant OCD vary from 20 to $60 \%$ of the population with the condition [26, 3540]. We were unable to identify prevalence data for treatment resistant bipolar affective disorder (whether depression or mania) or PTSD. Differences in the definitions of resistance between studies, as discussed above, are certain to substantially determine this variation. Another important factor is the population from which prevalence estimates are calculated, which can lead to ascertainment biases. For example, studies examining hospital populations with chronic illness are likely to record higher rates of treatment resistance compared with studies examining outpatient samples made of patients at the onset of illness.

In the USA, annual direct medical costs associated with TRS are conservatively estimated at over $\$ 34$ billion [41]. It has been estimated that hospitalisation costs and total health resource utilisations for TRS are 10-fold higher than those for non-TRS, and that up to $80 \%$ of the total yearly health costs associated with schizophrenia in the USA are attributed to TRS [41]. Direct medical costs associated with TRD are estimated to be 2-6 times higher compared with other patients with MDD [42, 43], with costs increasing with chronicity and severity of TRD [44]. Patients with TRD are twice as likely to be hospitalised compared with non-TRD patients, and require increased numbers of psychiatric outpatient visits [43]. Patients with TRS have more functional impairment in the community compared with other serious mental illnesses [45], and the mean quality of life is estimated to be $20 \%$ lower in TRS compared with non-TRS [41]. Mean quality of life is approximately $25-40 \%$ lower in patients with TRD compared with patients who respond to treatment or who are in remission [46], and 30\% of TRD patients attempt suicide in their lifetime [47].

\section{The neurobiology of treatment resistance}

There are three broad disease models proposed by the literature to explain treatment resistance, summarised in Fig. 5 (see eAppendix 3 for search details) [48-51]. The first possibility (Fig. $5 \mathrm{~A}$ ) is that the treatment resistant form of a given psychiatric illness has the same underlying neurobiology as the treatment responsive illness, but the pathophysiological alterations are more severe such that standard treatment is inadequate. This is partly supported by evidence that resistant symptoms of depression and schizophrenia may improve with higher doses of treatment in some patients [52-54]. Furthermore, as discussed above, secondary treatment resistance may be a consequence of either progressive neurobiological changes (pathoplasty) or iatrogenic effects. For example, in schizophrenia, an upregulation in dopamine D2/3 receptor levels with treatment could mean that a given antipsychotic dose is no longer enough to block dopaminergic neurotransmission adequately, leading to breakthrough resistant symptoms and necessitating higher doses [48].

Alternatively, treatment resistance could be neurobiologically distinct from treatment responsive illness (Fig. 5B). Supporting this, in some individuals, their illness shows little or no benefit from adequate treatment from illness onset despite evidence of high target engagement $[55,56]$, and there is some evidence of neurobiological differences between patients with TRS or TRD [57-59]. For example, studies using proton magnetic resonance spectroscopy have observed that levels of glutamatergic metabolites are particularly elevated in the anterior cingulate cortex in TRS compared to levels in patients, who respond to antipsychotic treatment and healthy controls and genetic and post-mortem studies also implicate glutamatergic pathways in TRS [60-62]. It should also be recognised that secondary treatment resistance may theoretically be a consequence of iatrogenic-change in neurotransmitter systems other than those primarily targeted by drugs, owing to off-target receptor actions.

The third possibility (Fig. $5 \mathrm{C}$ ) is a hybrid model where patients show a combination of both the same pathophysiology as responsive illness and additional neurobiological alterations meaning that standard treatment is inadequate. One example is that of immune dysregulation. Converging lines of genetic, postmortem, and pre-clinical evidence suggest immune dysregulation may play a role in the pathogenesis of both schizophrenia [63-67] and depression [68, 69], and it is hypothesised that immune alterations are seen only in a proportion of these patients (immune/inflammatory subgroups) and are linked to poor treatment response $[67,70-72]$. For example, in depression, levels of C-reactive protein (CRP) are higher in TRD compared with those who respond to antidepressant treatment [73]. Furthermore, some [74], but not all [75], clinical trials examining immunotherapy in depression have observed efficacy only in patients with peripheral inflammation. Immune dysregulation has been implicated in dysregulation of multiple neurotransmitter systems [76-78] that some antipsychotic and antidepressant agents may not therapeutically target. Thus, without specifically targeting immune dysregulation alongside conventional therapy, symptoms will persist. This highlights the need to better understand the neurobiology of treatment resistance to help guide treatment design. Furthermore, it introduces the possibility that drugs previously deemed ineffective on a group-level may yet provide benefit to subgroups of patients.

\section{Therapeutic approaches to treatment resistance}

For a drug to be considered in the management of treatment resistant psychiatric illness, its efficacy and specificity for use in treatment resistance must be demonstrated. Although studies that test drugs against placebo (or with no treatment) control for 


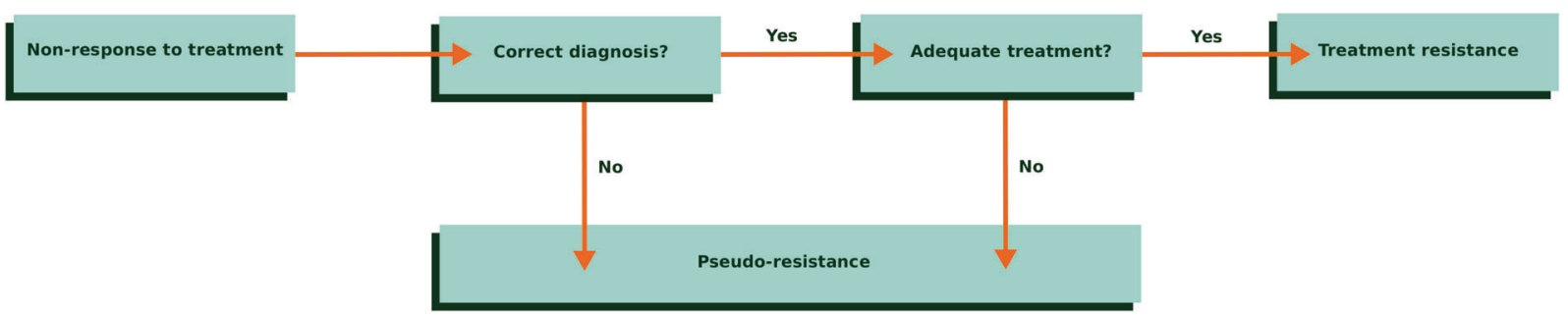

Fig. 4 Algorithm for approaching non-response to treatment in psychiatric illness. Persistent symptoms despite treatment could be due to treatment resistance or due to other factors that give the impression of treatment resistance when in fact adequate treatment has not been received (pseudo-resistance). Pseudo-resistance may be secondary to an incorrect primary diagnosis/psychiatric comorbidity/substance abuse, or be treatment related, including poor treatment adherence, malabsorption of drug, poor blood brain barrier penetrance of drug or fast metabolism of drug (see Table 2 and Fig. 3 ).

the scenario where symptoms improve with time, they do not control for the fact that longer treatment duration with an existing medication may lead to response. Thus, to demonstrate efficacy, the agent should demonstrate superiority over active comparators. Pharmacotherapy strategies for treatment resistance can be divided into two groups: monotherapies and adjunctive strategies.

To date, the only drug that has been licensed as monotherapy for a treatment resistant condition in psychiatry is clozapine for TRS, which gained regulatory approval on the basis of two studies $[12,79]$. Although clozapine is a dopamine antagonist, relative to other antipsychotics it exhibits low D2 dopamine receptor occupancy [80], suggesting that disease model 1 is unlikely and modulation of other neurotransmitter systems may play a therapeutic role [81]. This is most in keeping with disease model 2 of treatment resistance described above (Fig. 5B), although it should be recognised that this needs testing and the mode of action of clozapine for TRS remains unclear.

Two adjunctive strategies for treatment resistance have been approved, both for TRD. Esketamine in combination with antidepressant therapy has recently received approval in both the US and Europe [82]. Esketamine blocks the NMDA receptor channel, and there is evidence that it induces plastic changes at glutamate synapses to improve connectivity [83], and may also affect other neurotransmitters [84]. The novel mechanism of action and efficacy of esketamine as an adjunct to conventional antidepressants (serotonin/norepinephrine reuptake inhibitors) are in keeping with disease model 3 (Fig. 5C). In the US, olanzapine combined with fluoxetine is a licensed therapy for TRD. FDA approval was based on data from studies that examined the olanzapine/fluoxetine combination compared with olanzapine or fluoxetine monotherapy [85-87]. These studies were 8-weeks in duration, and defined TRD as depression meeting DSM-IV criteria with persistence of symptoms despite at least two different antidepressant trials, including a prospective course of fluoxetine monotherapy. In all trials, depressive symptoms of patients who met criteria for treatment resistance improved significantly more when treated with the olanzapine/fluoxetine combination versus olanzapine or fluoxetine monotherapy. There is also evidence that adjunctive aripiprazole alongside antidepressant therapy is effective in people with MDD and inadequate response to antidepressant monotherapy [88]; furthermore, the magnitude of symptomatic improvement with adjunctive therapy was observed to be greater in those with only minimal response to antidepressant monotherapy compared to those with partial response [88]. The superior efficacy of combination therapy points towards patients with TRD presenting with a combination of the same neurochemical abnormality seen in first-line treatment responders with an additional neurochemical dysfunction, which is most in keeping with disease model 3 of treatment resistance detailed above (Fig. 5C).

As mentioned above, there is also some evidence that high doses of certain antidepressants (e.g., venlafaxine) [53, 89] or antipsychotics (e.g., olanzapine) [52] can be effective strategies in the management of treatment resistant depression and schizophrenia respectively. In the case of venlafaxine, there is evidence that increasing the dose beyond $150 \mathrm{mg} /$ day results in a greater effect on noradrenergic neurotransmission [90]. This approach is most in keeping with disease model 1 of treatment resistance detailed above (Fig. 5A), although it should be recognised that, at higher doses, drug actions at other receptors may become more important.

In terms of neuro-stimulatory treatments, the FDA has approved use of transcranial magnetic stimulation in the treatment of MDD in patients who have failed to achieve 'satisfactory improvement from one prior antidepressant medication' [91]. However, it is unclear if such a definition reliably describes true treatment resistance (see 'Current definitions of treatment resistance across disorders' section above), and the FDA warns that efficacy of transcranial magnetic stimulation has not been established in patients with 'varying degrees of medication resistance'. Electroconvulsive therapy (ECT) has widespread regulatory approval for treatment resistant depression and mania. The mechanism by which ECT effects response where medication has been unsuccessful remains poorly defined, but may stem from alterations in cerebral blood flow and regional metabolism [92]. This novel mechanism of action is in keeping with disease model 2 of treatment resistance detailed above (Fig. 5B).

\section{New treatment directions}

To identify new treatments in the pipeline, we searched clinicaltrials.gov for phase 2 and 3 studies examining novel agents and interventions specifically for treatment resistant depression, schizophrenia, bipolar affective disorder, OCD, panic disorder, post-traumatic stress disorder, and substance dependence (see eAppendix 4 for search details). We identified 15 studies currently recruiting, covering treatments for schizophrenia, depression, bipolar affective disorder, and OCD. These are summarised in Table 3 (see eTable 2 for further details). They all have estimated completion dates within the next 2 years. Where stated, all the pharmacological interventions are adjunctive strategies, other than a clinical trial of LuAF35700 (an antagonist at dopaminergic, serotonergic and a-adrenergic receptors) as monotherapy for TRS that has just been completed. The headline results of this study indicate that it failed to demonstrate superiority over risperidone or olanzapine (clinical trials identifier: NCT02717195), although the full trial results remain to be published. In terms of nonpharmacological interventions, we identified studies examining transcranial magnetic stimulation in schizophrenia, vagus nerve stimulation in depression, deep brain stimulation in MDD and OCD, and radio-surgical (gamma capsulotomy) interventions in OCD.

\section{Outstanding issues and future directions}

There are several outstanding issues in the field of psychiatric treatment resistance (Table 4). As discussed in the overview of 

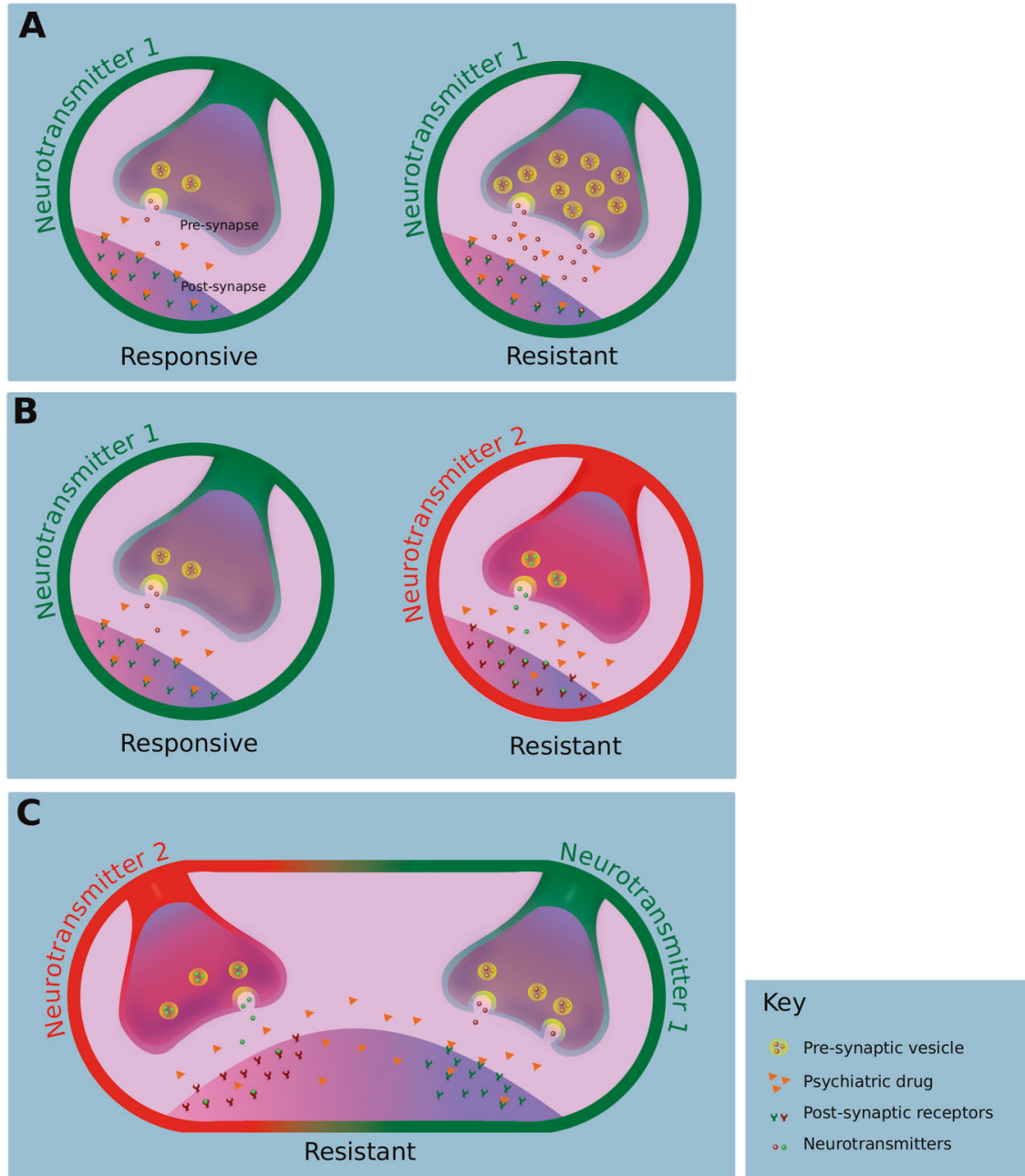

Fig. 5 Main putative disease models to explain treatment resistance in psychiatry. A Treatment responsive and resistant illnesses are defined by the same neurobiological alterations (neurotransmitter 1), however the alterations are more marked in patients with treatment resistance. As such, higher doses of drugs targeting neurotransmitter system 1 (orange triangles) are required for therapeutic benefit. B Treatment responsive and resistant illnesses are defined by different underlying neurobiological mechanisms, for example two different neurotransmitter systems (neurotransmitters 1 and 2). As such, a drug targeting only neurotransmitter system 1 will be ineffective in patients with dysregulation in neurotransmitter system 2. C Treatment resistance arises from a combination of neurobiological alterations seen in responsive illness (neurotransmitter 1 ) in combination with a different neurobiological process (neurotransmitter 2). As such, treatments that act on both targets are likely to be needed.

operationalised descriptions of treatment resistance, there is marked heterogeneity in definitions used. This could lead to heterogeneity of study populations, which in turns limits the validity of research. Furthermore, for certain conditions such as mania, anxiety disorders, and PTSD, consensus definitions of resistance have yet to be agreed, and for some other conditions, such as autism spectrum disorder, there are no licenced drugs for core symptoms, thus, by definition, there is no treatment resistance. Although here we have predominantly focused on resistance to drug treatments, similar limitations apply to psychological and other therapies (e.g., in defining adequate treatment duration/number of psychology sessions). Furthermore, most approaches to treatment resistance consider the illness in terms of a single over-arching symptom dimension. However, these fail to recognise that some patients may have ongoing domain-specific disabling symptoms despite treatment, such as negative symptoms of schizophrenia or somatic symptoms of depression. Thus, the definitions of treatment resistance based on global rating may exclude people with one very disabling nonresponsive symptom. Moreover, the imperfect nature of symptom rating scales may mean that degree of disability associated with some ratings of symptom severity are not captured. Finally, in the context of recognised phenomenological overlap between various psychiatric conditions, a transdiagnostic approach focussed on symptom domains, such as psychosis in schizophrenia and bipolar affective disorder, or depression in major depressive disorder and bipolar affective disorder [93], might help disentangle common underlying mechanisms linked to response and resistance. Clear objectives for the field are therefore to agree and adopt unified definitions of treatment resistance for each disorder, and to consider treatment resistance in terms of specific symptom domains (as already recommended by some definitions) [22] and their associated disability.

We identified circumstances that could lead to an illness being mistaken as treatment resistant, when non-response is in fact related to factors such as misdiagnosis or non-adherence (pseudoresistance). Importantly, these factors are often not systematically assessed in research or clinical practice. Future work on identifying pseudo-resistance in the clinic and defining assessment pathways would be useful.

Greater understanding of the pathoaetiology of treatment resistance in psychiatric disorders could help identify new targets 
Table 4. Outstanding issues and future directions for research and clinical practice in the field of psychiatric treatment resistance.

\section{Outstanding Issues}

Marked heterogeneity in the definitions of treatment resistance provided by clinical guidelines, including in:

- definitions of adequate treatment trials (e.g., drug dose and duration)

- Number of treatment trials needed

- Differentiation between non-response and partial response

This will lead to the potential for inappropriate treatment decisions and bias in clinical trials

Absence of clear definitions of treatment resistance for various psychiatric conditions

The neurobiology of treatment resistance in all psychiatric conditions remains unclear

The number of studies published annually on the topic of treatment resistance in psychiatry, although increasing, remains small (approximately $0.5 \%$ of papers published in the field of psychiatry in 2019). There is a paucity of treatments, particularly monotherapies, targeting treatment resistant symptoms in psychiatry

\section{Proposed solutions and future directions}

- Revision of definitions of treatment resistance to ensure greater specificity. Included in this effort should be recommendations to quantitatively assess treatment response and attempts to improve identification of pseudo-resistance e.g., through drug plasma monitoring to assess adherence

- Harmonisation of definitions of treatment resistance across clinical guidelines

- Clinical trials to cite criteria by which treatment resistance is defined and use reporting checklists for treatment resistance (see Box 1)

- Definition of treatment resistance in conditions such as mania and post-traumatic stress disorder will facilitate appropriate clinical care and research

- Efforts to determine the neural mechanisms underlying treatment resistance would help guide targeted and potentially personalised treatment approaches

- Given that the prevalence of treatment resistance is up to $60 \%$ in some psychiatric populations, not to mention the significant associated economic and societal costs, more resources should be directed towards research in psychiatric treatment resistance and novel therapeutics.

- Clinical trials in treatment resistance should aim to examine novel monotherapies versus an active comparator.

- There is evidence that drugs already licenced for certain psychiatric disorders may have therapeutic potential in other treatment resistant psychiatric illnesses, e.g., clozapine for treatment resistant mania. Future clinical trials are required to establish an evidence base for their use in this context. to guide the development of novel treatments. It could also help develop biomarkers to identify subgroups of patients with specific biological alterations that may benefit from tailored interventions earlier in the illness course, and to guide patient selection and evaluate target engagement in clinical trials. Furthermore, improved understanding of the mechanisms underlying different psychiatric symptom domains will provide insight into the transdiagnostic nature of their neurobiology and thus potential for overlapping treatments. Efforts to identify TRS based on genetics and neuroimaging are on-going [61,94], and there has been considerable recent interest in stratifying patients with schizophrenia and depression based on blood immune markers with a view to identifying a subgroup whose psychiatric symptoms may respond to immunotherapy [67, 74, 75].

Strikingly, although the number of studies published annually on the topic of treatment resistance has increased over the last decade, the proportion of the literature dedicated to the topic of remains small (approximately $0.5 \%$ in 2019, see Fig. 1 and eAppendix 1). Given that the prevalence of treatment resistance in psychiatric conditions is $20-60 \%$, and it is associated with high burden, there is a clear need for greater resources to be directed towards research in psychiatric treatment resistance.

\section{CONCLUSIONS}

Treatment resistance comprises the trinity of establishing the correct psychiatric diagnosis, adequate treatment (in terms of dose and duration), and inadequate symptomatic response. It is commonly seen in many psychiatric disorders and associated with substantial functional impairment and economic and social costs. Whilst there has been a marked increase in research and industry interest in treatment resistance, the proportion of psychiatric research in this field remains very low relative to its burden. There is both marked variation and lack of clear criteria in the definition of treatment resistance both within and between disorders, which could lead to heterogeneity in the patients included in studies, making comparisons difficult. This highlights the need for greater consistency and operationalisation in the definitions of treatment resistance used, and we have provided a reporting checklist that future clinical trials can use to demonstrate on what basis patients with treatment resistance are recruited. There are only three pharmacological interventions licensed for treatment resistance, and only one, clozapine, licenced as a monotherapy. However, fifteen novel interventions are currently being examined in clinical trials of treatment resistant psychiatric conditions. Future drug development and clinical care will be informed by our improved understanding of the neurobiology of treatment resistance, and by employing various neuroimaging, molecular, and genetic techniques, may pave the way for precision medicine in the field.

\section{REFERENCES}

1. Mead BT, Ellsworth RB, Grimmett JO. The treatment of drug-resistive chronicschizophrenics. J Nerv Ment Dis. 1958;127:351-8.

2. Haskovec L, Rysanek K. The action of reserpine in imipramine-resistant depressive patients. Psychopharmacologia. 1967;11:18-30.

3. Davidson J, McLeod M, Law-Yone B, Linnoila M. A comparison of electroconvulsive therapy and combined phenelzine-amitriptyline in refractory depression. Arch Gen Psychiatry. 1978;35:639-42.

4. Gitlin M. Treatment-resistant bipolar disorder. Mol Psychiatry. 2006;11:227-40.

5. Bloch $\mathrm{MH}$, Storch EA. Assessment and management of treatment-refractory obsessive-compulsive disorder in children. J Am Acad Child Adolesc Psychiatry. 2015;54:251-62.

6. Canuso CM, Singh JB, Fedgchin M, Alphs L, Lane R, Lim P, et al. Efficacy and safety of intranasal esketamine for the rapid reduction of symptoms of depression and suicidality in patients at imminent risk for suicide: results of a double-blind, randomized, placebo-controlled study. Am J Psychiatry. 2018;175:620-30.

7. Singh JB, Fedgchin M, Daly EJ, De Boer P, Cooper K, Lim P, et al. A double-blind, randomized, placebo-controlled, dose-frequency study of intravenous ketamine in patients with treatment-resistant depression. Am J Psychiatry. 2016;173:816-26.

8. ClinicalTrials.gov. Effect of Lu AF35700 in patients with treatment-resistant schizophrenia (DayBreak) [ClinicalTrials.gov Identifier: NCT02717195]. 2016.

9. Hamburg MA, Collins FS. The path to personalized medicine. N. Engl J Med. 2010;363:301-4. 
10. Freud S. A General Introduction to Psychoanalysis (Williams \& Wilkins, 1920).

11. Jones MS. Coma resistance and adrenalæmia in the insulin treatment of schizophrenia: (Section of Psychiatry). Proc R Soc Med. 1939;32:958-68.

12. Kane J, Honigfeld G, Singer J, Meltzer H. Clozapine for the treatment-resistant schizophrenic. A double-blind comparison with chlorpromazine. Arch Gen Psychiatry. 1988;45:789-96.

13. Leucht S, Samara M, Heres S, Patel MX, Woods SW, Davis JM. Dose equivalents for second-generation antipsychotics: the minimum effective dose method. Schizophr. Bull. 2014;40:314-26.

14. Brissos S, Veguilla MR, Taylor D, Balanza-Martinez V. The role of long-acting injectable antipsychotics in schizophrenia: a critical appraisal. Ther Adv Psychopharmacol. 2014;4:198-219.

15. Citrome L. New second-generation long-acting injectable antipsychotics for the treatment of schizophrenia. Expert Rev Neurother. 2013;13:767-83.

16. Guo X, McCutcheon RA, Pillinger T, Mizuno Y, Natesan S, Brown K, et al. The magnitude and heterogeneity of antidepressant response in depression: a meta-analysis of over 45,000 patients. J Affect Disord. 2020;276:991-1000.

17. Samara MT, Dold M, Gianatsi M, Nikolakopoulou A, Helfer B, Salanti G, et al. Efficacy, acceptability, and tolerability of antipsychotics in treatment-resistant schizophrenia: a network meta-analysis. JAMA Psychiatry. 2016;73:199-210.

18. Mizuno Y, McCutcheon RA, Brugger SP, Howes OD. Heterogeneity and efficacy of antipsychotic treatment for schizophrenia with or without treatment resistance: a meta-analysis. Neuropsychopharmacology. 2020;45:622-31.

19. Rodriguez P, Holowka DW, Marx BP. Assessment of posttraumatic stress disorder-related functional impairment: a review. J Rehabil Res Dev. 2012;49:649-65.

20. Soyka M, Mutschler J. Treatment-refractory substance use disorder: focus on alcohol, opioids, and cocaine. Prog Neuro-Psychopharmacol Biol Psychiatry. 2016;70:148-61.

21. Sanderson WC, Bruce TJ. Causes and management of treatment-resistant panic disorder and agoraphobia: a survey of expert therapists. Cogn Behav Pract. 2007; 14:26-35.

22. Howes OD, McCutcheon R, Agid O, de Bartolomeis A, van Beveren NJM, Birnbaum $\mathrm{ML}$, et al. Treatment-resistant schizophrenia: treatment response and resistance in psychosis (TRRIP) working group consensus guidelines on diagnosis and terminology. Am J Psychiatry. 2017;174:216-29.

23. McCutcheon R, Beck K, Bloomfield MAP, Marques TR, Rogdaki M, Howes OD. Treatment resistant or resistant to treatment? Antipsychotic plasma levels in patients with poorly controlled psychotic symptoms. J Psychopharmacol. 2015;29:892-7.

24. Lingam R, Scott J. Treatment non-adherence in affective disorders. Acta Psychiatr Scand. 2002;105:164-72.

25. Demjaha A, Lappin JM, Stahl D, Patel MX, MacCabe JH, Howes OD, et al. Antipsychotic treatment resistance in first-episode psychosis: prevalence, subtypes and predictors. Psychol Med. 2017;47:1981-9.

26. Lally J, Ajnakina O, Di Forti M, Trotta A, Demjaha A, Kolliakou A, et al. Two distinct patterns of treatment resistance: clinical predictors of treatment resistance in first-episode schizophrenia spectrum psychoses. Psychol Med. 2016;46:3231-40.

27. Rutherford BR, Wager TD, Roose SP. Expectancy and the treatment of depression: a review of experimental methodology and effects on patient outcome. Curr Psychiatry Rev. 2010;6:1-10.

28. Baca-Garcia E, Perez-Rodriguez MM, Basurte-Villamor I, Fernandez del Moral AL, Jimenez-Arriero MA, Gonzalez de Rivera JL, et al. Diagnostic stability of psychiatric disorders in clinical practice. Br J Psychiatry. 2007;190:210-6.

29. Sachs GS, Nierenberg AA, Calabrese JR, Marangell LB, Wisniewski SR, Gyulai L, et al. Effectiveness of adjunctive antidepressant treatment for bipolar depression. N Engl J Med. 2007;356:1711-22.

30. Terao $\mathrm{T}$, Ishii $\mathrm{N}$, Hirakawa $\mathrm{H}$, Aoshima $\mathrm{E}$. Is the bell-shaped dose-response curve of the selective serotonin reuptake inhibitor due to 5-HT1A auto-receptors? Med Hypotheses. 2020;140:109681.

31. O'Dwyer AM, Marks I. Obsessive-compulsive disorder and delusions revisited. $\mathrm{Br}$ J Psychiatry. 2000;176:281-4.

32. King $\mathrm{BH}$, Lord C. Is schizophrenia on the autism spectrum? Brain Res. 2011;1380:34-41.

33. Angst J, Gamma A, Benazzi F, Ajdacic V, Eich D, Rossler W. Toward a re-definition of subthreshold bipolarity: epidemiology and proposed criteria for bipolar-II, minor bipolar disorders and hypomania. J Affect Disord. 2003;73:133-46.

34. Smith DJ, Griffiths E, Kelly M, Hood K, Craddock N, Simpson SA. Unrecognised bipolar disorder in primary care patients with depression. $\mathrm{Br} J$ Psychiatry. 2011;199:49-56.

35. Rasmussen SA, Eisen JL, Pato MT. Current issues in the pharmacologic management of obsessive compulsive disorder. J Clin Psychiatry. 1993;54:4-9.

36. Essock SM, Hargreaves WA, Dohm FA, Goethe J, Carver L, Hipshman L. Clozapine eligibility among state hospital patients. Schizophr Bull. 1996;22:15-25.
37. Wimberley T, Stovring H, Sorensen HJ, Horsdal HT, MacCabe JH, Gasse C. Predictors of treatment resistance in patients with schizophrenia: a populationbased cohort study. Lancet Psychiatry. 2016;3:358-66.

38. Rush AJ, Trivedi MH, Wisniewski SR, Nierenberg AA, Stewart JW, Warden D, et al. Acute and longer-term outcomes in depressed outpatients requiring one or several treatment steps: a STAR*D report. Am J Psychiatry. 2006;163:1905-17.

39. Souery D, Oswald P, Massat I, Bailer U, Bollen J, Demyttenaere K, et al. Clinical factors associated with treatment resistance in major depressive disorder: results from a European multicenter study. J Clin Psychiatry. 2007; 68:1062-70.

40. Rizvi SJ, Grima E, Tan M, Rotzinger S, Lin P, Mclntyre RS, et al. Treatmentresistant depression in primary care across Canada. Can J Psychiatry. 2014;59:349-57.

41. Kennedy JL, Altar CA, Taylor DL, Degtiar I, Hornberger JC. The social and economic burden of treatment-resistant schizophrenia: a systematic literature review. Int Clin Psychopharmacol. 2014;29:63-76.

42. Corey-Lisle PK, Birnbaum HG, Greenberg PE, Marynchenko MB, Claxton AJ. Identification of a claims data "signature" and economic consequences for treatment-resistant depression. J Clin Psychiatry. 2002;63:717-26.

43. Crown WH, Finkelstein S, Berndt ER, Ling D, Poret AW, Rush AJ, et al. The impact of treatment-resistant depression on health care utilization and costs. J Clin Psychiatry. 2002;63:963-71.

44. Reich D, Nalls MA, Kao WHL, Akylbekova EL, Tandon A, Patterson N et al. Reduced neutrophil count in people of African descent is due to a regulatory variant in the duffy antigen receptor for chemokines gene. PLoS Genet. 2009;5: e1000360.

45. lasevoli F, Giordano S, Balletta R, Latte G, Formato MV, Prinzivalli E et al. Treatment resistant schizophrenia is associated with the worst community functioning among severely-ill highly-disabling psychiatric conditions and is the most relevant predictor of poorer achievements in functional milestones. Prog. Neuro-Psychopharmacol. Biol. Psychiatry 2016;65,34-48.

46. Mrazek DA, Hornberger JC, Altar CA, Degtiar I. A review of the clinical, economic, and societal burden of treatment-resistant depression: 1996-2013. Psychiatr Serv. 2014;65:977-87.

47. Bergfeld IO, Mantione M, Figee M, Schuurman PR, Lok A, Denys D. Treatmentresistant depression and suicidality. J Affect Disord. 2018;235:362-7.

48. Potkin SG, Kane JM, Correll CU, Lindenmayer JP, Agid O, Marder SR, et al. The neurobiology of treatment-resistant schizophrenia: paths to antipsychotic resistance and a roadmap for future research. NPJ Schizophr. 2020;6:1.

49. Trivedi $\mathrm{MH}$, Hollander $\mathrm{E}$, Nutt $\mathrm{D}$, Blier P. Clinical evidence and potential neurobiological underpinnings of unresolved symptoms of depression. J Clin Psychiatry. 2008;69:246-58.

50. Sanacora G, Treccani G, Popoli M. Towards a glutamate hypothesis of depression: an emerging frontier of neuropsychopharmacology for mood disorders. Neuropharmacology. 2012;62:63-77.

51. Coplan JD, Gopinath S, Abdallah CG, Berry BR. A neurobiological hypothesis of treatment-resistant depression - mechanisms for selective serotonin reuptake inhibitor non-efficacy. Front Behav Neurosci. 2014;8:189.

52. Lerner V. High-dose olanzapine for treatment-refractory schizophrenia. Clin Neuropharmacol. 2003;26:58-61.

53. Poirier MF, Boyer $\mathrm{P}$. Venlafaxine and paroxetine in treatment-resistant depression-double-blind, randomised comparison. Br J Psychiatry. 1999;175:12-16.

54. Adli M, Baethge C, Heinz A, Langlitz N, Bauer M. Is dose escalation of antidepressants a rational strategy after a medium-dose treatment has failed? A systematic review. Eur Arch Psychiatry Clin Neurosci. 2005;255:387-400.

55. Kapur S, Zipursky R, Jones C, Remington G, Houle S. Relationship between dopamine $\mathrm{D}(2)$ occupancy, clinical response, and side effects: a double-blind PET study of first-episode schizophrenia. Am J Psychiatry. 2000;157:514-20.

56. Lanzenberger R, Kranz GS, Haeusler D, Akimova E, Savli M, Hahn A, et al. Prediction of SSRI treatment response in major depression based on serotonin transporter interplay between median raphe nucleus and projection areas. Neuroimage. 2012;63:874-81.

57. Demjaha A, Murray RM, McGuire PK, Kapur S, Howes OD. Dopamine synthesis capacity in patients with treatment-resistant schizophrenia. Am J Psychiatry. 2012;169:1203-10.

58. Howes OD, Kapur S. A neurobiological hypothesis for the classification of schizophrenia: type A (hyperdopaminergic) and type B (normodopaminergic). Br J Psychiatry. 2014;205:1-3.

59. Duman RS, Aghajanian GK, Sanacora G, Krystal JH. Synaptic plasticity and depression: new insights from stress and rapid-acting antidepressants. Nat Med. 2016:22:238-49.

60. Demjaha A, Egerton A, Murray RM, Kapur S, Howes OD, Stone JM, et al. Antipsychotic treatment resistance in schizophrenia associated with elevated glutamate levels but normal dopamine function. Biol Psychiatry. 2014; 75:e11-13. 
61. Pillinger $T$, Rogdaki M, McCutcheon RA, Hathway $P$, Egerton A, Howes OD. Altered glutamatergic response and functional connectivity in treatment resistant schizophrenia: the effect of riluzole and therapeutic implications. Psychopharmacology. 2019;236:1985-97.

62. Potkin SG, Kane JM, Correll CU, Lindenmayer JP, Agid O, Marder SR, et al. The neurobiology of treatment-resistant schizophrenia: paths to antipsychotic resistance and a roadmap for future research. Focus. 2020;18:456-65.

63. Howes OD, McCutcheon R. Inflammation and the neural diathesis-stress hypothesis of schizophrenia: a reconceptualization. Transl Psychiatry. 2017;7: e1024.

64. Schizophrenia Working Group of the Psychiatric Genomics Consortium. Biological insights from 108 schizophrenia-associated genetic loci. Nature 2014;511:421-7.

65. Marques TR, Ashok AH, Pillinger T, Veronese M, Turkheimer FE, Dazzan P et al. Neuroinflammation in schizophrenia: meta-analysis of in vivo microglial imaging studies. Psychol Med. 2018;49:1-11.

66. Pillinger T, D'Ambrosio $E_{1}$ McCutcheon R, Howes OD. Is psychosis a multisystem disorder? A meta-review of central nervous system, immune, cardiometabolic, and endocrine alterations in first-episode psychosis and perspective on potential models. Mol Psychiatry. 2018;24:776-94.

67. Pillinger T, Osimo EF, Brugger S, Mondelli V, McCutcheon RA, Howes OD. A meta-analysis of immune parameters, variability, and assessment of modal distribution in psychosis and test of the immune subgroup hypothesis. Schizophr Bull. 2018;45:1120-33.

68. Dantzer R, O'Connor JC, Freund GG, Johnson RW, Kelley KW. From inflammation to sickness and depression: when the immune system subjugates the brain. Nat Rev Neurosci. 2008;9:46-56.

69. Benros ME, Waltoft BL, Nordentoft M, Ostergaard SD, Eaton WW, Krogh J, et al. Autoimmune diseases and severe infections as risk factors for mood disorders a nationwide study. Jama Psychiatry. 2013;70:812-20.

70. Mondelli V, Ciufolini S, Murri MB, Bonaccorso S, Di Forti M, Giordano A, et al. Cortisol and inflammatory biomarkers predict poor treatment response in first episode psychosis. Schizophr. Bull. 2015;41:1162-70.

71. Fillman SG, Weickert TW, Lenroot RK, Catts SV, Bruggemann JM, Catts VS, et al. Elevated peripheral cytokines characterize a subgroup of people with schizophrenia displaying poor verbal fluency and reduced Broca's area volume. Mol Psychiatry. 2016;21:1090-8.

72. Osimo EF, Pillinger T, Rodriguez IM, Khandaker GM, Pariante CM, Howes OD. Inflammatory markers in depression: a meta-analysis of mean differences and variability in 5166 patients and 5,083 controls. Brain Behav Immun. 2020;87:901-9.

73. Chamberlain SR, Cavanagh J, de Boer P, Mondelli V, Jones DNC, Drevets WC, et al. Treatment-resistant depression and peripheral C-reactive protein. $\mathrm{Br} J$ Psychiatry. 2019;214:11-19.

74. Raison CL, Rutherford RE, Woolwine BJ, Shuo C, Schettler P, Drake DF, et al. A randomized controlled trial of the tumor necrosis factor antagonist infliximab for treatment-resistant depression: the role of baseline inflammatory biomarkers. JAMA Psychiatry. 2013;70:31-41.

75. McIntyre RS, Subramaniapillai M, Lee $Y$, Pan Z, Carmona NE, Shekotikhina M et al. Efficacy of adjunctive infliximab vs placebo in the treatment of adults with bipolar I/II depression: a randomized clinical trial. JAMA Psychiatry 2019;76:783-90.

76. Steiner J, Bogerts B, Sarnyai Z, Walter M, Gos T, Bernstein HG, et al. Bridging the gap between the immune and glutamate hypotheses of schizophrenia and major depression: Potential role of glial NMDA receptor modulators and impaired blood-brain barrier integrity. World J Biol Psychiatry. 2012;13:482-92.

77. Mueller N, Schwarz MJ. The immune-mediated alteration of serotonin and glutamate: towards an integrated view of depression. Mol Psychiatry. 2007;12:988-1000.

78. Muller N, Weidinger E, Leitner B, Schwarz MJ. The role of inflammation in schizophrenia. Front Neurosci. 2015;9:372.

79. Claghorn JL, Abuzzahab FS, Wang R, Larson C, Gelenberg AJ, Klerman GL, et al. The current status of clozapine. Psychopharmacol Bull. 1983;19:138-40.

80. Yilmaz Z, Zai CC, Hwang R, Mann S, Arenovich T, Remington G, et al. Antipsychotics, dopamine $\mathrm{D}(2)$ receptor occupancy and clinical improvement in schizophrenia: a meta-analysis. Schizophr Res. 2012;140:214-20.

81. Kaar SJ, Natesan S, McCutcheon R, Howes OD Antipsychotics: mechanisms underlying clinical response and side-effects and novel treatment approaches based on pathophysiology. Neuropharmacology 2019;172:107704.

82. Jauhar S, Morrison P. Esketamine for treatment resistant depression. BMJ. 2019;366:15572.

83. Kavalali ET, Monteggia LM. Synaptic mechanisms underlying rapid antidepressant action of ketamine. Am J Psychiatry. 2012;169:1150-6.

84. Kokkinou $M$, Ashok $A H$, Howes OD. The effects of ketamine on dopaminergic function: meta-analysis and review of the implications for neuropsychiatric disorders. Mol Psychiatry. 2018;23:59-69.
85. Thase ME, Corya SA, Osuntokun O, Case M, Henley DB, Sanger TM, et al. A randomized, double-blind comparison of olanzapine/fluoxetine combination, olanzapine, and fluoxetine in treatment-resistant major depressive disorder. J Clin Psychiatry. 2007;68:224-36.

86. Shelton RC, Tollefson GD, Tohen M, Stahl S, Gannon KS, Jacobs TG, et al. A novel augmentation strategy for treating resistant major depression. Am J Psychiatry. 2001;158:131-4.

87. Shelton RC, Williamson DJ, Corya SA, Sanger TM, Van Campen LE, Case M, et al. Olanzapine/fluoxetine combination for treatment-resistant depression: a controlled study of SSRI and nortriptyline resistance. J Clin Psychiatry. 2005;66:1289-97.

88. Thase ME, Trivedi MH, Nelson JC, Fava M, Swanink R, Tran QV, et al. Examining the efficacy of adjunctive aripiprazole in major depressive disorder: a pooled analysis of 2 studies. Prim Care Comp J Clin Psychiatry. 2008;10:440-7.

89. Nierenberg AA, Feighner JP, Rudolph R, Cole JO, Sullivan J. Venlafaxine for treatment-resistant unipolar depression. J Clin Psychopharmacol. 1994;14:419-423.

90. Owens MJ, Krulewicz S, Simon JS, Sheehan DV, Thase ME, Carpenter DJ, et al. Estimates of serotonin and norepinephrine transporter inhibition in depressed patients treated with paroxetine or venlafaxine. Neuropsychopharmacology. 2008;33:3201-3212.

91. FDA. U.S. Food \& Drug Administration. Repetitive Transcranial Magnetic Stimulation (rTMS) Systems-Class II Special Controls Guidance for Industry and FDA Staff. https://www.fda.gov/medical-devices/guidance-documents-medicaldevices-and-radiation-emitting-products/repetitive-transcranial-magneticstimulation-rtms-systems-class-ii-special-controls-guidance\#1; 2011.

92. Fosse R, Read J. Electroconvulsive treatment: hypotheses about mechanisms of action. Front Psychiatry. 2013;4:94.

93. Jauhar S, Nour MM, Veronese M, Rogdaki M, Bonoldi I, Azis M, et al. A test of the transdiagnostic dopamine hypothesis of psychosis using positron emission tomographic imaging in bipolar affective disorder and schizophrenia. JAMA Psychiatry. 2017;74:1206-1213.

94. Wimberley T, Gasse C, Meier SM, Agerbo E, MacCabe JH, Horsdal HT. Polygenic risk score for schizophrenia and treatment-resistant schizophrenia. Schizophr Bull. 2017;43:1064-1069.

95. Lehman AF, Lieberman JA, Dixon LB, McGlashan TH, Miller AL, Perkins DO, et al. Practice guideline for the treatment of patients with schizophrenia, second edition. Am J Psychiatry. 2004;161:1-56.

96. Barnes TRE, Psychopharmacology BA. Evidence-based guidelines for the pharmacological treatment of schizophrenia: recommendations from the British Association for Psychopharmacology. J Psychopharmacol. 2011;25:567-620.

97. IPAP. International Psychopharmacology Algorithm Project (www.ipap.org): Schizophrenia Algorithm Flowchart. 2019.

98. Taylor D, Barnes T, Young A. The maudsley prescribing guidelines in psychiatry 13th edn. Wiley Blackwell; 2018.

99. Verma S, Chan LL, Chee KS, Chen H, Chin SA, Chong SA, et al. Ministry of Health Clinical Practice Guidelines: Schizophrenia. Singap Med J. 2011;52:521-525.

100. NICE. Psychosis and schizophrenia in adults: prevention and management, CG178. 2014.

101. McGorry P, Killackey E, Lambert T, Lambert M, Jackson H, Codyre D, et al. Royal Australian and New Zealand College of Psychiatrists clinical practice guidelines for the treatment of schizophrenia and related disorders. Aust NZ J Psychiatry. 2005;39:1-30.

102. Falkai P, Wobrock T, Lieberman J, Glenthoj B, Gattaz WF, Moller HJ, et al. World Federation of Societies of Biological Psychiatry (WFSBP)-Guidelines for biological treatment of schizophrenia, part 1: Acute treatment of schizophrenia. World J Biol Psychiatry. 2005;6:132-91.

103. Practice guideline for major depressive disorder in adults. American Psychiatric Association. Am J Psychiatry. 1993;150:1-26.

104. Gelenberg A, Freeman MP, Markowitz J, Rosenbaum JF, Thase M, Madhukar T et al. Practice guideline for the treatment of patients with major depressive disorder, 3rd edn. American Psychiatric Association; 2010.

105. Cleare A, Pariante CM, Young AH, Anderson IM, Christmas D, Cowen PJ, et al. Evidence-based guidelines for treating depressive disorders with antidepressants: a revision of the 2008 British Association for Psychopharmacology guidelines. J Psychopharmacol. 2015;29:459-525.

106. Kennedy SH, Lam RW, Mclntyre RS, Tourjman SV, Bhat V, Blier $\mathrm{P}$, et al. Canadian Network for Mood and Anxiety Treatments (CANMAT) 2016 Clinical Guidelines for the management of adults with major depressive disorder: section 3 . pharmacological treatments. Can J Psychiatry. 2016;61:540-60.

107. Milev RV, Giacobbe P, Kennedy SH, Blumberger DM, Daskalakis ZJ, Downar J, et al. Canadian Network for Mood and Anxiety Treatments (CANMAT) 2016 Clinical Guidelines for the management of adults with major depressive disorder: section 4. neurostimulation treatments. Can J Psychiatry. 2016;61:561-75.

108. Schosser A, Serretti A, Souery D, Mendlewicz J, Zohar J, Montgomery S, et al. European Group for the Study of Resistant Depression (GSRD) - Where have we 
gone so far: review of clinical and genetic findings. Eur Neuropsychopharmacol. 2012;22:453-68.

109. Hamilton M. A rating scale for depression. J Neurol Neurosurg Psychiatry. 1960;23:56-62.

110. McAllister-Williams RH, Christmas DMB, Cleare AJ, Currie A, Gledhill J, Insole L, et al. Multiple-therapy-resistant major depressive disorder: a clinically important concept. Br J Psychiatry. 2018;212:274-8.

111. Chua HC, Chan LL, Chee KS, Chen YH, Chin SA, Chua PLW, et al. Ministry of Health Clinical Practice Guidelines: depression. Singap Med J. 2012;53:137-43.

112. NICE Depression in adults: recognition and management. National Institute for Clinical Excellence. CG90 (updated April 2018). 2009.

113. Malhi GS, Bassett D, Boyce P, Bryant R, Fitzgerald PB, Fritz K, et al. Royal Australian and New Zealand College of Psychiatrists clinical practice guidelines for mood disorders. Aust N Z J Psychiatry. 2015;49:1087-206.

114. Bauer M, Severus E, Moller HJ, Young AH. Disorders WTFoUD. Pharmacological treatment of unipolar depressive disorders: summary of WFSBP guidelines. Int J Psychiatry Clin Pr. 2017;21:166-76.

115. Hidalgo-Mazzei D, Berk M, Cipriani A, Cleare AJ, Di Florio A, Dietch D, et al. Treatment-resistant and multi-therapy-resistant criteria for bipolar depression: consensus definition. Br J Psychiatry. 2019;214:27-35.

116. Geller DA \& March J. Practice parameter for the assessment and treatment of children and adolescents with obsessive-compulsive disorder. J Am Acad Child Adolesc Psychiatry. 2012;51:98-113.

117. Pallanti S, Hollander E, Bienstock C, Koran L, Leckman J, Marazziti D, et al. Treatment non-response in OCD: methodological issues and operational definitions. Int J Neuropsychopharmacol. 2002;5:181-91.

118. Mataix-Cols D, Fernandez de la Cruz L, Nordsletten AE, Lenhard F, Isomura K, Simpson HB. Towards an international expert consensus for defining treatment response, remission, recovery and relapse in obsessive-compulsive disorder. World Psychiatry. 2016;15:80.

119. Hollister LE. Monitoring tricyclic antidepressant plasma concentrations. JAMA. 1979;241:2530-3.

120. Nikisch G, Baumann $P$, Oneda B, Kiessling B, Weisser $H$, Mathe AA, et al. Cytochrome $\mathrm{P} 450$ and $A B C B 1$ genetics: association with quetiapine and norquetiapine plasma and cerebrospinal fluid concentrations and with clinical response in patients suffering from schizophrenia. A pilot study. J Psychopharmacol. 2011;25:896-907.

121. Uhr M, Tontsch A, Namendorf C, Ripke S, Lucae S, Ising $M$, et al. Polymorphisms in the drug transporter gene $A B C B 1$ predict antidepressant treatment response in depression. Neuron. 2008;57:203-9.

122. Perera V, Gross AS, Polasek TM, Qin Y, Rao G, Forrest A, et al. Considering CYP1A2 phenotype and genotype for optimizing the dose of olanzapine in the management of schizophrenia. Expert Opin Drug Met. 2013;9:1115-37.

123. Baumann P, Broly F, Kosel M, Eap CB. Ultrarapid metabolism of clomipramine in a therapy-resistant depressive patient, as confirmed by CYP2 D6 genotyping. Pharmacopsychiatry. 1998;31:72-72.

124. Skogh E, Reis M, Dahl ML, Lundmark J, Bengtsson F. Therapeutic drug monitoring data on olanzapine and its $\mathrm{N}$-demethyl metabolite in the naturalistic clinical setting. Ther Drug Monit. 2002;24:518-26.

125. Leinonen $E$, Lillsunde $P$, Laukkanen $V$, Ylitalo $P$. Effects of carbamazepine on serum antidepressant concentrations in psychiatric-patients. J Clin Psychopharmacol. 1991;11:313-8.

126. Fabbri C, Tansey KE, Perlis RH, Hauser J, Henigsberg N, Maier W, et al. Effect of cytochrome CYP2C19 metabolizing activity on antidepressant response and side effects: meta-analysis of data from genome-wide association studies. Eur Neuropsychopharmacol. 2018;28:945-54.

127. Wagner $E$, McMahon L, Falkai $P$, Hasan A, Siskind D. Impact of smoking behavior on clozapine blood levels-a systematic review and meta-analysis. Acta Psychiatr Scand. 2020;142:456-66.

128. Augustin M, Schoretsanitis G, Hiemke C, Grunder G, Haen E, Paulzen M. Differences in duloxetine dosing strategies in smoking and nonsmoking patients: therapeutic drug monitoring uncovers the impact on drug metabolism. J Clin Psychiatry. 2018;79:5.

129. Patel MX, Bowskill S, Couchman L, Lay V, Taylor D, Spencer EP, et al. Plasma olanzapine in relation to prescribed dose and other factors: data from a therapeutic drug monitoring service, 1999-2009. J Clin Psychopharmacol. 2011;31:411-7.

130. Kokras N, Dalla C, Papadopoulou-Daifoti Z. Sex differences in pharmacokinetics of antidepressants. Expert Opin Drug Met. 2011;7:213-26.

\section{ACKNOWLEDGEMENTS}

This study was funded by Medical Research Council-UK (no. MC_A656_5QD30_2135), Maudsley Charity (no. 666), and Wellcome Trust (no. 094849/Z/10/Z) grants to Professor Howes and the National Institute for Health Research (NIHR) Biomedical Research Centre at South London and Maudsley NHS Foundation Trust and King's College London. Dr Pillinger is supported by the NIHR and Maudsley Charity. The funders had no role in study design, data collection, data analysis, data interpretation, or writing of the report. The views expressed are those of the author(s) and not necessarily those of $\mathrm{H}$ Lundbeck $\mathrm{A} / \mathrm{s}$, the NHS/NIHR or the Department of Health. Funding was provided by UK Medical Research Council, Wellcome Trust, National Institute for Health Research.

\section{COMPETING INTERESTS}

Professor Howes is a part-time employee of $H$ Lundbeck $A / s$ and has received investigator-initiated research funding from and/or participated in advisory/ speaker meetings organised by Angellini, Autifony, Biogen, Boehringer-Ingelheim, Eli Lilly, Heptares, Global Medical Education, Invicro, Jansenn, Lundbeck, Neurocrine, Otsuka, Sunovion, Rand, Recordati, Roche and Viatris/Mylan. Neither Professor Howes nor his family have holdings or a financial stake in any pharmaceutical company. Professor Howes has a patent for the use of dopaminergic imaging. Dr Pillinger has participated in speaker meetings organised by Lundbeck, Otsuka, Sunovion, Schwabe Pharma and Recordati. Professor Thase has served as an adviser or consultant for Acadia, Akili, Alkermes, Allergan (Forest, Naurex), Boehringer-Ingelheim, Calla, Cerecor, Clexio Biosciences, Fabre-Kramer Pharmaceuticals, Gerson Lehrman Group, Guidepoint Global, H. Lundbeck A/S, Jazz Pharmaceuticals, Janssen (Johnson \& Johnson), Moksha8 Pharmaceuticals, Nestle, Neuralstem, Novartis International AG, Otsuka Pharmaceutical Company, Perception Neuroscience, Pfizer, Sage Therapeutics, Seelos Therapeutics, Sunovion Pharmaceuticals, and Takeda; he has received grant support from Acadia, the Agency for Healthcare Research and Quality, Alkermes, Allergan (Forest, Naurex), AssureRx Health, Avanir, Axsome Therapeutics, Intracellular, Janssen Pharmaceutica (Johnson \& Johnson), Myriad (Assurex), NIMH, Otsuka Pharmaceutical Company, the Patient Centered Outcomes Research Institute, and Takeda; and he has received royalties from American Psychiatric Press, Inc., Guilford Publications, Herald House, and W.W. Norton \& Company. His spouse is a Vice President of Open Health (formerly Peloton Advantage), which does business with a number of pharmaceutical companies.

\section{ADDITIONAL INFORMATION}

Supplementary information The online version contains supplementary material available at https://doi.org/10.1038/s41380-021-01200-3.

Correspondence and requests for materials should be addressed to O.D.H.

Reprints and permission information is available at http://www.nature.com/ reprints

Publisher's note Springer Nature remains neutral with regard to jurisdictional claims in published maps and institutional affiliations.

Open Access This article is licensed under a Creative Commons Attribution 4.0 International License, which permits use, sharing, adaptation, distribution and reproduction in any medium or format, as long as you give appropriate credit to the original author(s) and the source, provide a link to the Creative Commons license, and indicate if changes were made. The images or other third party material in this article are included in the article's Creative Commons license, unless indicated otherwise in a credit line to the material. If material is not included in the article's Creative Commons license and your intended use is not permitted by statutory regulation or exceeds the permitted use, you will need to obtain permission directly from the copyright holder. To view a copy of this license, visit http://creativecommons. org/licenses/by/4.0/.

(c) The Author(s) 2021 